\title{
Nanotechnology and picotechnology to increase tissue growth: a summary of in vivo studies
}

\author{
This article was published in the following Dove Press journal: \\ International Journal of Nanomedicine \\ 5 May 2014 \\ Number of times this article has been viewed
}

\author{
Ece Alpaslan' \\ Thomas J Webster ${ }^{1,2}$ \\ 'Department of Chemical Engineering, \\ College of Engineering, Northeastern \\ University, Boston, MA, USA; ${ }^{2}$ Center \\ of Excellence for Advanced Materials \\ Research, King Abdulaziz University, \\ Jeddah, Saudi Arabia
}

\begin{abstract}
The aim of tissue engineering is to develop functional substitutes for damaged tissues or malfunctioning organs. Since only nanomaterials can mimic the surface properties (ie, roughness) of natural tissues and have tunable properties (such as mechanical, magnetic, electrical, optical, and other properties), they are good candidates for increasing tissue growth, minimizing inflammation, and inhibiting infection. Recently, the use of nanomaterials in various tissue engineering applications has demonstrated improved tissue growth compared to what has been achieved until today with our conventional micron structured materials. This short report paper will summarize some of the more relevant advancements nanomaterials have made in regenerative medicine, specifically improving bone and bladder tissue growth. Moreover, this short report paper will also address the continued potential risks and toxicity concerns, which need to be accurately addressed by the use of nanomaterials. Lastly, this paper will emphasize a new field, picotechnology, in which researchers are altering electron distributions around atoms to promote surface energy to achieve similar increased tissue growth, decreased inflammation, and inhibited infection without potential nanomaterial toxicity concerns.
\end{abstract}

Keywords: nanomaterials, tissue engineering, toxicity

\section{Introduction}

Bone tissue and other organ dysfunction can be provoked by poor eating habits, stress, age-related diseases such as osteoarthritis or osteoporosis, as well as accidents. ${ }^{1}$ To date, common procedures to restore or enhance life expectancy involve medical device insertion or organ transplantation. ${ }^{1}$ However, due to the low number of donors and its high cost, organ transplantation is limited. Many people will die before they are actually able to get an organ for transplantation. ${ }^{2}$ Moreover, the traditional materials that are used as medical devices are micron structured and do not emulate many (if any) properties of natural tissues. As such, they have limited lifetimes, sometimes failing before the end of the patient's lifetime. ${ }^{1}$

Nanotissue engineering arises as an alternative to organ transplantation and the use of conventional medical devices, aiming to develop biological substitutes that can restore, maintain, or improve damaged tissues and organs. ${ }^{2,3}$ As a general strategy, in tissue engineering, rather than introducing cells into the diseased area, the cells are seeded within a three-dimensional biomaterial, which is also called a scaffold, to promote reorganization of seeded cells in order to form a functional tissue. ${ }^{2,3}$

Until very recently, these scaffolds have been designed to provide structural integrity on the macro- or microscopic scale, but it has been observed that structural
Correspondence: Thomas J Webster Department of Chemical Engineering, College of Engineering, Northeastern University, 360 Huntington Avenue, Boston, 02115 MA, USA

Email th.webster@neu.edu 
integrity itself is not enough to properly regenerate tissues. ${ }^{2}$ Recently, research groups have started to focus on the surface roughness of the scaffolds, as well to emulate natural tissues. ${ }^{4}$ Now, efforts have turned to designing both biocompatible and biodegradable nanostructured tissue engineering scaffolds with proper mechanical and surface properties to engineer tissues. $^{4}$

The motivation for the use of nanotechnology in tissue engineering comes from biology itself. Within tissues, cells support and are directed by an extracellular matrix (ECM). The ECM plays a vital role in storing, releasing, and activating a wide range of biological factors. In order to promote the successful regeneration of tissues, engineering biomaterials in a way that can emulate the ECM is crucial. ${ }^{5}$ Designing a biomimetic material at the nanoscale (defined as using or creating materials with one dimension less $100 \mathrm{~nm}$ ) that can be compatible with cells to effectively and efficiently recreate the ECM, has been relatively easy with the recent advances in nanotechnology. ${ }^{5}$

These nanotechnologies have been applied to create nanofeatured scaffolds, nanotopographical surfaces, and controlled drug release systems, as well as to manage cellular behavior that ranges from improving cell adhesion to gene expression. ${ }^{6}$ Living cells are very sensitive to nanoscale patterns and topographical differences within the ECM. ${ }^{7}$ In order to control cell functions, engineered substrates with nanofeatures have become widely adopted by many research groups. ${ }^{7}$ Numerous techniques have been utilized in order to create a variety of nanotopographical features (Figure 1). Specifically, techniques like lithography, anodization, and electrospinning can be used to create nanospheres, nanotubes, or nanofibers in the vertical direction. ${ }^{8}$ In order to obtain less ordered nanofeatures, chemical etching, polymer mixing, or electrospinning can also be used. ${ }^{8}$

Over the years, various types of conventional materials have been explored in nanotissue engineering (such as polymers, ceramics, metals, and inorganic materials). ${ }^{8}$ Even though some metals may seem like they are good candidates to act as scaffolds because of their optimal mechanical properties, for the most part, metals (except magnesium) lack noncorrosionrelated degradability for their widespread use in tissue engineering; thus, such nonbiodegradable metals persist in the body, causing a constant potential stimuli that may lead to harmful inflammation. Also, some inorganic/ceramic materials, such as hydroxyapatite (HAP) and calcium phosphates, are also being studied because of their good osteoconductivity properties. ${ }^{9}$

In vivo, the chosen material needs to provide mechanical support sufficient enough to withstand the exerted forces by the surrounding tissue and promote tissue development. ${ }^{10}$

\section{Nanomaterials for bone tissue applications}

According to the American Academy of Orthopedic Surgeons, within 9-year time span (2000-2009), the number of total hip

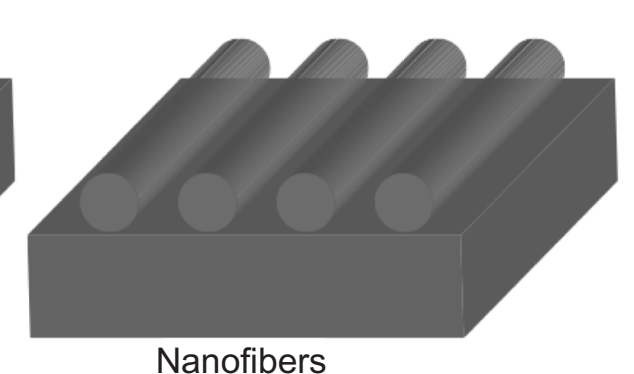

Nanogratings

Nanofibers

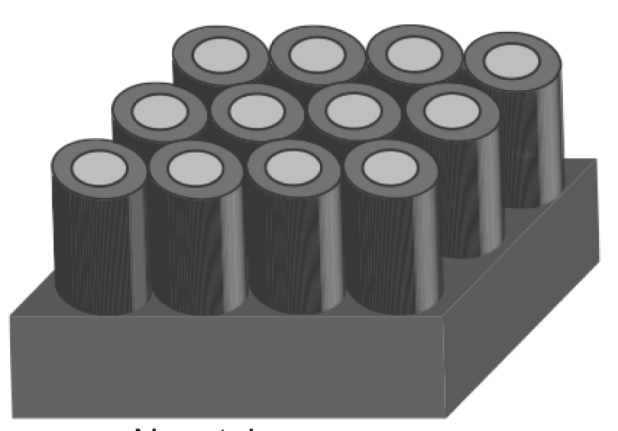

Nanotubes

Figure I Schematic of different nanofeatures. 
replacements increased by nearly $73 \%,{ }^{11}$ but the lifetime of a traditional implant material remains around $10-15$ years. ${ }^{12}$ There is clearly an urgent need to develop novel materials that will last the lifetime of a patient.

Bone is a nanocomposite material that consists of a protein-based soft hydrogel template and hard inorganic components. ${ }^{12-14}$ In addition to the dimensional similarity between bone/cartilage tissue and a nanofeatured material, these materials also have unique surface properties such as surface roughness, chemistry, and wettability due to their increased surface area when compared to conventional or micron-sized materials. ${ }^{13}$ When designing a novel material for an orthopedic implant, another important parameter that needs to be considered is promoting sufficient osseointegration between the designed material and tissue. Recent studies showed that the surface properties of nanotextured materials enhance the adhesion of cells by interacting with certain types of proteins like fibronectin, vitronectin, and laminin to stimulate the efficient growth of bone. ${ }^{13}$ This key mechanism explains the superiority of nanomaterials over conventional materials (Figure 2).

Various kinds of materials, such as nanophase ceramics, polymers, metals, and composites, can be utilized for bone/ cartilage tissue engineering applications by controlling their surface properties. For instance, nanohydroxyapatite is known to promote mineralization; therefore, this material is referred to as a popular bone substitute. Having a grain size at the nanometer scale and a high surface fraction of grain boundaries provides nanoceramics with unique properties to increase osteoblast functions. ${ }^{13}$ For example, a comparison between $179 \mathrm{~nm}$ grain sized HAP to $67 \mathrm{~nm}$ grain sized HAP after 4 hours of culture revealed that the $67 \mathrm{~nm}$ grain sized HAP significantly increased osteoblast adhesion. ${ }^{15}$ In another study, performed by Nukavarapu et al, ${ }^{16}$ HAP/ polyphosphazane microsphere three-dimensional scaffolds that have suitable mechanical and cytocompatible properties were fabricated, which showed promise for orthopedic applications.

These results are also supported by in vivo studies. Studies on rats demonstrated that nanocrystalline HAP accelerates new bone formation on tantalum scaffolds. ${ }^{15,16}$ When the amount of new bone growth in the rat calvaria on uncoated tantalum was compared with conventional HAPcoated tantalum and nanocrystalline HAP-coated tantalum, nanocrystalline HAP-coated tantalum showed greater amounts of new bone growth. ${ }^{17}$ Different nanoceramics such as $\mathrm{ZnO}, \mathrm{TiO}_{2}$, and $\mathrm{Al}_{2} \mathrm{O}_{3}$ also showed similarities in the rate of new bone growth, which suggests that surface features have a stronger effect on bone growth in comparison to surface chemistry. ${ }^{18}$

In one study, a nanocomposite material made of poly(propylene fumarate) and single-walled carbon nanotubes (CNTs) were explored for potential use as a scaffold material. ${ }^{19}$ Results showed inferior mechanical properties of single-walled CNTs reinforced the mechanical properties of the polymer greatly by the presence of poly(propylene fumarate) and increased osteoconductivity due to enhanced cell attachment and proliferation. Although this system may appear to be a good candidate to investigate further, there are concerns about the toxicity of CNTs (and, for that matter, all
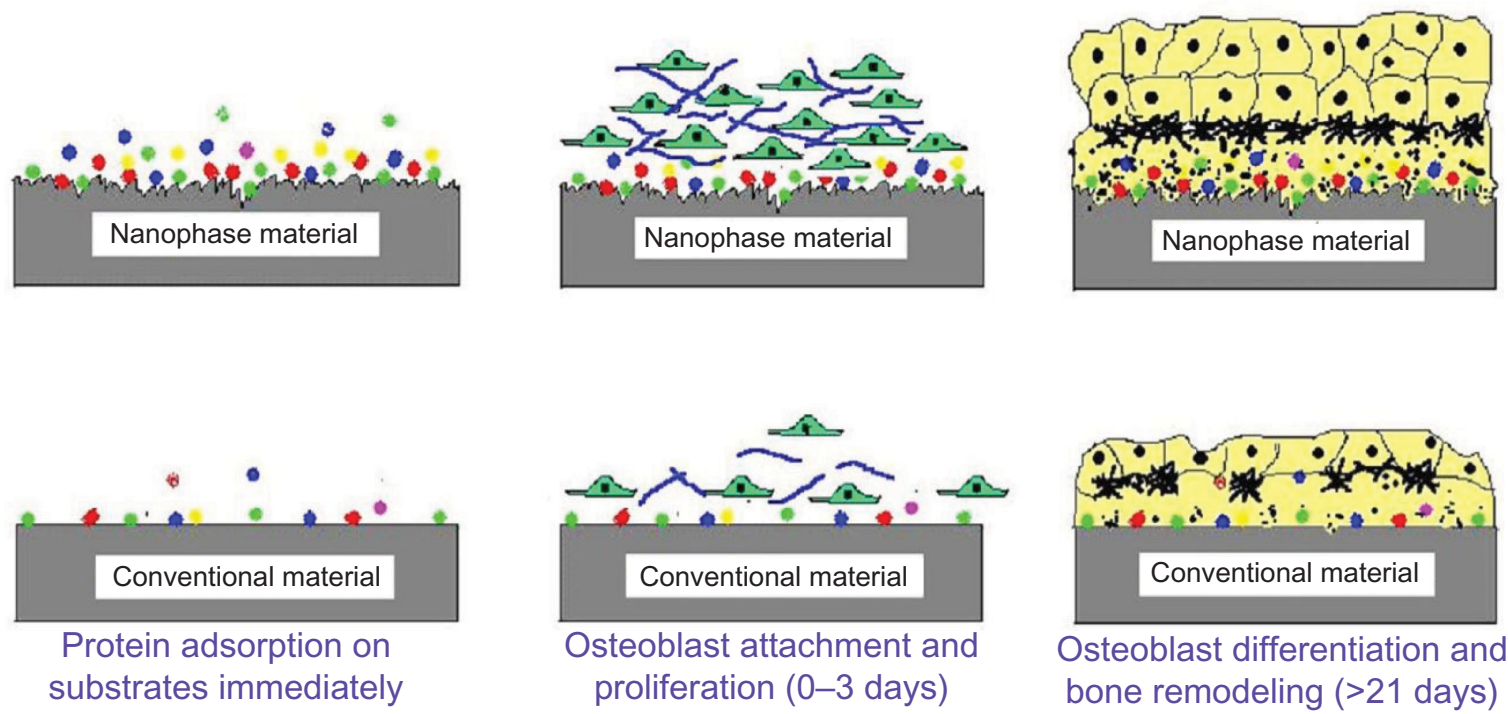

Figure 2 Schematic of one possible explanation for the superiority of nanofeatured material, as opposed to conventional materials, in tissue engineering. Notes: Reprinted from Nano Today, Volume 4(I), Zhang L, Webster TJ, Nanotechnology and nanomaterials: promises for improved tissue regeneration, pages 66-80, Copyright 2009 with permission from Elsevier. ${ }^{12}$ 
nanomaterials), which will be discussed in the "Nanomaterials and their potential risks toward human health" section.

\section{Nanomaterials for bladder tissue applications}

There are numerous conditions of the bladder that may lead to a loss of function. In this way, nanomaterials can also be used as soft tissue implants. As just one of many examples, bladder tissue will be described here. Bladder cancer is the fourth most common type of cancer in the United States, and thus urinary bladder tissue implants are common surgeries. ${ }^{20}$ Urinary bladder tissue implants often suffer from insufficient cell coverage of the implant material with the surrounding tissue. $^{21}$

Nanotextured polymer scaffolds with superior biocompatibility properties have been widely investigated as materials for urinary bladder applications. Additionally, their potential to withstand forces exerted by the pelvic muscles from urine storage, or as the patient conducts daily activities, leads to difficulty in restoring healthy bladder tissue. ${ }^{10}$ To achieve this appropriate choice of regeneration, degradation and mechanical properties are crucial. For example, Thapa et al and Pattison et $\mathrm{al}^{22-24}$ developed nanotextured poly(lacticco-glycolic) acid and poly(ether urethane) films by chemical etching. This study revealed for the first time how polymeric nanorough surface features enhanced bladder cell proliferation. Some preliminary in vivo results further showed that nanostructured polymer scaffolds formed little to no calcium stones, which is one of the major problems following bladder implant surgery. ${ }^{12}$

In addition using biocompatible nanofibrous electrospun polycaprolactone (PCL) with polylactic acid and PCL significantly improved levels of cell infiltration and tissue formation. They carried out their experiments in vivo and used canines in their studies. According to their experiments, PCL/polylactic acid demonstrated better clinical results after 4 months, due to normal mucosal appearance without encrustation. $^{23}$

\section{Nanomaterials and their potential risks toward human health}

In an admittedly short period of time, nanotechnology has achieved tremendous progress in medicine. Some nanomaterials are already used industrially. ${ }^{12}$ Commercially,

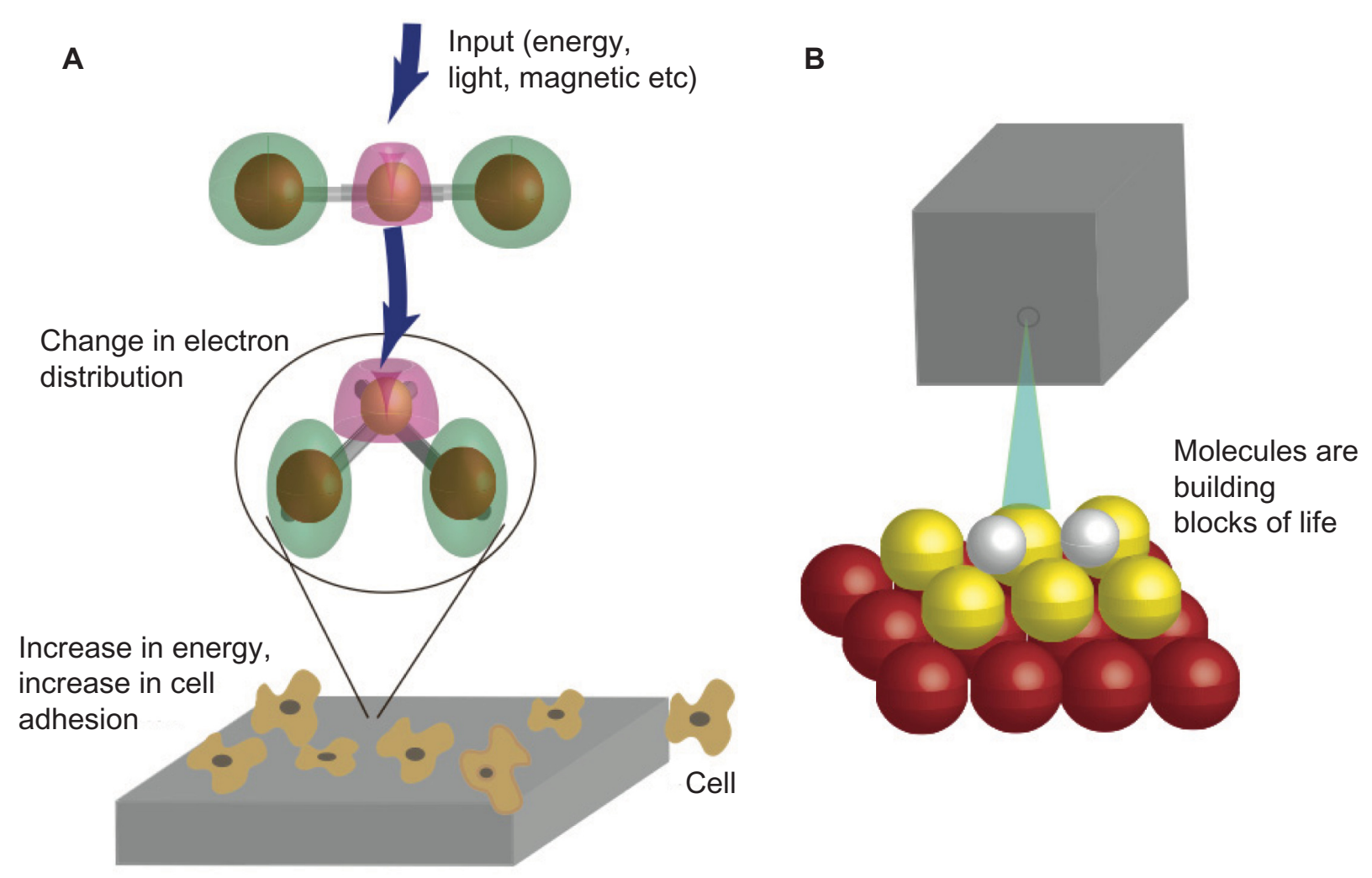

Figure 3 The promise of picotechnology.

Notes: (A) The promise of picotechnology: a schematic of changing electron distributions around atoms when stimulated by an external stimulus (energy, light, magnetic energy, etc). (B) The promise of nanotechnology: a schematic of how molecules stack together to form a structure, which can be controlled using nanotechnology. 
nanoceramics are available as new bone grafts or as implant coating materials. ${ }^{12}$ However, research on nanomaterials in tissue engineering and medical applications is still in its infancy. The effect of nanomaterials on human and environmental health is still not well understood. At this stage, more in vivo studies are needed. An in vivo study performed by Lam et $\mathrm{al}^{26}$ proved that CNTs are more toxic when compared to carbon black nanoparticles in the lungs. This may end up being a serious environmental health hazard upon inhalation exposure. Another item that needs to be considered is the interaction of nanoparticles with biomolecules in vivo and their aggregation state, which may be toxic to humans. ${ }^{12}$ The current state of research is still not enough to fully understand or explain the toxicity of nanomaterials in human and environmental health. However, it is critical that if nanomaterials are found to be toxic at the concentration that they are needed in the body, so as to improve a medical condition, research needs to be conducted to design these nanoparticles so they are not toxic.

\section{Looking forward: picotechnology}

A potentially less toxic method that is used to increase tissue growth and create the next generation of tissue engineering materials is to use picotechnology. Picotechnology is a new term used to describe the control of electron distribution around atoms, so as to provide desirable properties (Figure 3). Having control over electron distribution may greatly change surface energy and, thus, the way that proteins adsorb onto a material. Therefore, through the excitement or rearrangement of electrons around atoms, one has the ability to influence many cellular functions including cell movement, intracellular transport to organelles, adhesion, growth, and ECM formation.

Despite the promise of picotechnology, relatively little research has been conducted in this field. The control of cellular microtubules (MTs) through picotechnology is extremely interesting to consider. MTs are cylindrical cellular formations $25 \mathrm{~nm}$ in diameter, and they are made out of tubulins. Dynamic instability due to MT plus end-binding proteins, also called "plus end-tracking proteins", are able to "surf" the dynamic ends of MTs. According to recent reports, when tips are expressed as green fluorescent proteins, the fluorescence is the brightest at the MT and decreases in intensity toward the minus end of the MT, forming a comet tail. ${ }^{25-27}$ It is envisioned that one could use external stimulation to excite the MT and end-binding proteins to promote the movement of cells using picotechnology. This may be a less toxic manner through which to alter surface energy to increase tissue growth since electron distributions can be changed for numerous macro-, micro-, or nanomaterials.

\section{Conclusion}

The use of nanotechnology in tissue engineering has experienced exponential growth in the last decade. Nanostructured materials have proven to be useful in numerous in vitro and in vivo experiments. The synthesis and incorporation of new structures into biological molecules have led us to provide a biomimetic environment in which to develop tissue. Of course, there are still challenges that need to be addressed, which are mostly related to human and environmental toxicity. The use of inorganic nanomaterials (like CNTs) should be thoroughly investigated before they are clinically applied. But, importantly, if high toxicity is measured, one should not give up on those nanomaterials, but rather functionalize such nanoparticles to be less toxic. Future strategies may also include the use of picotechnology instead of nanotechnology to reduce the toxicity since electrons can be excited in any macro-, micro-, or nanomaterials. The change in electron distribution, along with the associated charge redistribution, can alter surface energetics to change the adsorption of certain proteins (as well as cellular functions).

\section{Disclosure}

The authors report no conflicts of interest in this work.

\section{References}

1. Perán M, García MA, Lopez-Ruiz E, Jiménez G, Marchal JA. How can nanotechnology help to repair the body? Advances in cardiac, skin, bone, cartilage and nerve tissue regeneration. Materials. 2013;6(4): 1333-1359.

2. Dvir T, Timko BP, Kohane DS, Langer R. Nanotechnological strategies for engineering complex tissues. Nat Nanotechnol. 2011;6(1):13-22.

3. Langer R, Vacanti JP. Tissue engineering. Science. 1993;260(5110): 920-926.

4. Lutolf MP, Hubbell JA. Synthetic biomaterials as instructive extracellular microenvironments for morphogenesis in tissue engineering. Nat Biotechnol. 2005;23(1):47-55.

5. Goldberg M, Langer R, Jia X. Nanostructured materials for applications in drug delivery and tissue engineering. J Biomater Sci Polym Ed. 2007;18(3):241-268.

6. Ferrari M. Cancer nanotechnology: opportunities and challenges. Nat Rev Cancer. 2005;5(3):161-171.

7. Ma PX. Biomimetic materials for tissue engineering. Adv Drug Deliv Rev. 2008;60(2):184-198.

8. Shi J, Votruba AR, Farokhzad OC, Langer R. Nanotechnology in drug delivery and tissue engineering: from discovery to applications. Nano Lett. 2010;10(9):3223-3230.

9. Yang S, Leong KF, Du Z, Chua CK. The design of scaffolds for use in tissue engineering. Part I. Traditional factors. Tissue Eng. 2001;7(6): 679-689.

10. Atala A. Tissue engineering of human bladder. Br Med Bull. 2011;97: 81-104.

11. American Academy of Orthopedic Surgeons (AAOS), online: http:// www.aaos-annualmeeting-presskit.org/2014/news_releases/artificial_hip_knee.shtml. Accessed March 31, 2014.

12. Zhang L, Webster TJ. Nanotechnology and nanomaterials: promises for improved tissue regeneration. Nano Today. 2009;4(1):66-80.

13. Webster TJ, Ying JY. Advances in Chemical Engineering. New York, NY: Academic Press; 2001:125-166. 
14. Basu B, Katti DS, Kumar A. Advanced Biomaterials: Fundamentals, Processing, and Applications. Hoboken, New Jersey: John Wiley \& Sons, Inc.; 2009.

15. Webster TJ, Ergun C, Doremus RH, Siegel RW, Bizios R. Specific proteins mediate enhanced osteoblast adhesion on nanophase ceramics. J Biomed Mater Res. 2000;51(3):475-483.

16. Nukavarapu SP, Kumbar SG, Brown JL, et al. Polyphosphazene/ nano-hydroxyapatite composite microsphere scaffolds for bone tissue engineering. Biomacromolecules. 2008;9(7):1818-1825.

17. Sato M. Nanophase Hydroxyapatite Coatings for Dental and Orthopedic Applications [dissertation]. Lafayette, IN: Purdue University; 2006.

18. Colon G, Ward BC, Webster TJ. Increased osteoblast and decreased Staphylococcus epidermidis functions on nanophase $\mathrm{ZnO}$ and $\mathrm{TiO} 2$. J Biomed Mater Res A. 2006;78(3):595-604.

19. Colon G, Ward BC, Webster TJ. Increased osteoblast and decreased Staphylococcus epidermis functions on nanophase $\mathrm{ZnO}$ and $\mathrm{TiO} 2$. J Biomed Mater Res A. 2006;78(3):595-604.

20. American Urological Association, https://www.auanet.org/education/ guidelines/bladder-cancer.cfm. Accessed March 31, 2014.

21. Alpaslan E, Ercan B, Webster TJ. Anodized $20 \mathrm{~nm}$ diameter nanotubular titanium for improved bladder stent applications. Int J Nanomedicine. 2011;6:219-225.
22. Thapa A, Miller DC, Webster TJ, Haberstroh KM. Nano-structured polymers enhance bladder smooth muscle cell function. Biomaterials. 2003;24(17):2915-2926.

23. Pattison M, Webster TJ, Leslie J, Kaefer M, Haberstroh KM. Evaluating the in vitro and in vivo efficacy of nano-structured polymers for bladder tissue replacement applications. Macromol Biosci. 2007;7(5): 690-700.

24. Pattison MA, Wurster S, Webster TJ, Haberstroh KM. Three-dimensional, nano-structured PLGA scaffolds for bladder tissue replacement applications. Biomaterials. 2005;26(15):2491-2500.

25. Shakhssalim N, Dehghan MM, Moghadasali R, Soltani MH, Shabani I, Soleimani M. Bladder tissue engineering using biocompatible nanofibrous electrospun constructs: feasibility and safety investigation. Urol J. 2012;9(1):410-419.

26. Lam CW, James JT, McCluskey R, Hunter RL. Pulmonary toxicity of single-wall carbon nanotubes in mice 7 and 90 days after intratracheal instillation. Toxicol Sci. 2004;77(1):126-134.

27. Sharma R, Sharma A, Chen CJ. Emerging trends of nanotechnology towards picotechnology: energy and biomolecules. Nature Precedings. Presented at Nanoscience and Technology Institute NANOTECH Annual Meeting 2008, 22 June 2008.
International Journal of Nanomedicine

\section{Publish your work in this journal}

The International Journal of Nanomedicine is an international, peerreviewed journal focusing on the application of nanotechnology in diagnostics, therapeutics, and drug delivery systems throughout the biomedical field. This journal is indexed on PubMed Central, MedLine, CAS, SciSearch $\AA$, Current Contents ${ }^{\circledR} /$ Clinical Medicine,

\section{Dovepress}

Journal Citation Reports/Science Edition, EMBase, Scopus and the Elsevier Bibliographic databases. The manuscript management system is completely online and includes a very quick and fair peer-review system, which is all easy to use. Visit http://www.dovepress.com/ testimonials.php to read real quotes from published authors. 